\title{
RESEARCH STUDY ON OPTIMIZATION OF CONSTRUCTIVE AND FUNCTIONAL ELEMENTS OF VERTICAL MIXERS USED TO OBTAIN MIXED FODDER
}

\author{
Gheorghe Stroescu, Anisoara Paun, Iulian Voicea, Catalin Persu, Andreea Matache, Florin Nenciu \\ National Institute of Research-Development for Machines and Installations Designed \\ to Agriculture and Food Industry, Romania \\ gigistroescu62@gmail.com, ani_paun@yahoo.com, voicea_iulian@yahoo.com, \\ persucatalin@yahoo.com, andmatache@yahoo.com, florin_nenciu2000@yahoo.com
}

\begin{abstract}
Animal husbandry is an essential branch of agriculture, being also an accurate indicator of the whole economy. This sector may generate important negative effects on the living standards of the population, which is reflected in the consumption of products. The rapid advances in science and technology give a new rhythm and meaning to the development of animal husbandry. A priority aspect envisaging animal nutrition strategy is the feeding base. One of the methods used to obtain high yields in the livestock sector is the administration of mixed fodder in animal diet. The evaluations performed showed that by using mixed fodder in the pig and poultry feed, an average increase of production by $25 \%$ can be obtained. Mixed fodder is a mixture of simple concentrated fodder and in rare cases several dehydrated fodder. Mixed fodder can be administered in the form of grinded material or granules. Obtaining good quality mixed fodder requires the use of technologies and technical equipment that lead to the production of a wide range of feed directly inside the zootechnical farm. Production of feed has to be made at high efficiency and quality levels, according to global requirements, with the lowest possible costs for farmers. An important factor in this regard is the process of mixing the components of the mixed fodder. The present paper presents the experimental results obtained in the evaluation of a fodder mixing equipment, testing several types of products. Determinations have been made, depending on several variables (constructive and functional elements, specific weight of the product in the mixture, material moisture, granulation, mixing time, mixing auger speed, number of components, etc.) determining the quality of the mixture based on the calcium carbonate content. The fodder mixer was tested in the following conditions: four constructive variants of feeding auger with diameter $d=220 \mathrm{~mm}$, spiral pitch $p=220,220,110$ and $165 \mathrm{~mm}$; four construction variants for the diameter of the coil (mixing part) $d: 400,300,300$ and $220 \mathrm{~mm}$; spiral pitch S: 300, 225, 150 and $165 \mathrm{~mm}$; three speeds: 200, 300 and $400 \mathrm{rpm}$; four mixing times: 3, 6, 9 and 15 minutes; four mixing ratios: 1:40, 1:80, 1:120 and $1: 200$. The best results were obtained for the following construction parameters: feeding and mixing auger variant 1 with a diameter of $400 \mathrm{~mm}$ and a pitch of $300 \mathrm{~mm}$; the optimum speed of the auger is $300 \mathrm{rpm}$; the best mixing time is 6 minutes; degree of homogeneity corresponding to the requirements for all mixing ratios between 1:40 and 1:200.
\end{abstract}

Keywords: animal food, recipe, mixing, technology.

\section{Introduction}

Rapid advances in science and technology are setting a new pace and a new direction for the development of the zootechnical sector. The intensification of animal husbandry and innovations in this field impose a reconsideration of the traditional feeding methods for physiological and technicaleconomic reasons. In order to prevent physiological balance disorders, it is necessary to keep the animals on a balanced diet, being very rigorous with the nutritional values. In order to achieve a full value nutritional feed, the following essential elements must be respected $[1 ; 2]$ :

- production of fodder assortments in sufficient quantities and of appropriate quality depending on the biological particularities and physiological requirements of animals, by fully capitalizing the natural conditions and the technical-material base of the animal husbandry units;

- orientation of animal feeding towards the use in maximum quantities of green and juicy fodder and a rational use of concentrated fodder;

- superior processing of feeding materials, including wastes from agriculture and the food industry, through the application of advanced technologies;

- scientific substantiation of fodder preparation in general and concentrated fodder in particular.

The main criterion for assessing the feed value is the response of animals, manifested by feed physiological and economic efficiency.

The main objective pursued in modern animal farm management is to achieve maximum yields with a high degree of feed conversion, this being determined mainly by two factors: the genetic potential of the animals and the nutritional value of the feed. 
The role of nutrition in animal husbandry processes [3; 4]. Animal nutrition has a particularly important role in:

- maintaining animal health; a balanced diet of nutrients is the main approach of preventing animal deficiency diseases that can cause significant economic damage. At the same time, an inadequate diet in terms of fodder content decreases the resistance of animals to the action of harmful factors and weather;

- reproduction, growth and development processes;

- the process of breed improvement; the activities envisaging the selection, or obtaining new lines, types and breeds, cannot reach their purpose without a diet corresponding to the breed characteristics of the animals;

- obtaining the planned productions and making the animal husbandry sector profitable. Without ensuring the raw material - the fodder - in the needed quantities and assortments and without ensuring the normal development of the physiological processes underlying the productions through a balanced feeding, the animals cannot capitalize their productive potential which constitutes a significant loss for the animal breeders.

The processing and preparation of fodder is performed in order to obtain a higher nutritional value, increase the degree of edibility and digestibility, for providing various and complete assortments of fodder recipes. By researching fodder through different methods of preparation, we favorably modify its physical, chemical and biological properties, which results in a better use of them on animals. The use of processed fodder has the following advantages [4]:

- the gustatory properties of fodder are improved, which lead to an increase of the edibility levels, thus reducing the losses through the remains of uneaten fodder;

- it improves the digestibility by 5-15\% both for concentrated fodder, and especially for coarse fodder;

- the nutritional value is increased by $5-10 \%$.

Fodder processing allows and favors the mechanization and automation of the preparation and distribution of the feed to animals. There are fodder mixtures that cannot be administered as animal feed without being processed, because they might adversely affect the health. There are also feeds (derived from cereal seeds) that have a higher efficiency in feeding animals after prior crushing and mixing with other components. Among the products intended for animal feed, concentrates occupy a special place, [2; 5]. Concentrated fodder is grouped into two large classes: simple and mixed fodder. Combined fodder is a mixture of simple concentrated fodder and in rare cases dehydrated fodder. Mixed fodder can be administered in the form of grind fodder or granules. The technologies for processing fodder from cereal seeds (Fig. 1) are based on the zootechnical requirements for each type of feed, corresponding to its destination. These technologies include a series of operations including mixing of the components of concentrated fodder. For preparing the mixed fodder in the zootechnical farms, a mixing equipment has been developed, which was tested in order to determine the main constructive and experimental parameters. Fodder mixing is done in order to homogenize the components of the feed, following the proportions established by the recipe. Also, the mixing allows introduction in the recipes of some fodder that cannot be administered alone in animal feed (flours of animal origin, mineral salts, products and residues from the pharmaceutical industry, antibiotics, etc.). The work aims through the experiments performed establishing the influence of the constructive characteristics of the mixer on the quality of the mixture, the duration of the mixture, the productivity of the mixer, the driving power, all correlated with the uniformity of the mixture. The nature of the change in the uniformity of the mixture is a kind of exponential mixing over time. Research on the analysis of the characteristics of materials used to obtain mixed fodder has been conducted in several preliminary studies [6-10]. From the analysis of the activity of scientists from other countries we would find that the problem was approached more theoretically than experimentally.

\section{Materials and methods}

Figure 1 describes the technologies used for obtaining mixed fodders, and it can be seen that almost all of these technologies include the mixing operation. 
Figure 2 describes the experimental model of fodder flour production installation - IPFF. The installation is composed of a vertical grain mixer, a hammer mill, associated with a fodder mixer (for flour), having a recurrent action and being provided with a feeding and mixing auger. In the mixing process the components are homogenized according to the pre-established recipes (mixing ratios) depending on the animal breed. By mixing ratio is meant the ratio between the weight of the material to be added (microelements, minerals, etc.) and the weight of the base material (corn, barley, peas, etc.). The mixed fodder mixer (Figure $2 \mathrm{~b}$ ) consists of the following components: power box (1), (designed for the cases when it is used independently of the installation); auger coil (2); body mixer (3); discharge chute (4); frame (5); electric motor (6); driving system (7); bearing (8). The auger shaft is supported on both the upper and lower part on bearings. The drive system that is transmitting the motion from the motor to the mixer shaft is made by means of two wheels provided with two trapezoidal belts.

A frequency converter was used to achieve the speeds mentioned in the paper; $P_{n}=3.7 \mathrm{~kW}$, $I_{n}=8.0 \mathrm{~A}$ in overload regime.



Fig. 1. Technologies used for obtaining concentrated fodder from cereal seeds [4; 5]

The technological efficiency of the mixer in the homogenization process is established more precisely if calcium carbonate is used as an addition in the mixing ratios, because it represents the preponderant element that is blended with the basic products. Efficiency can be assessed by using the following two procedures [11]:

- based on the dispersion of the sample compositions, which can be expressed by weight;

- based on the dispersion of particles (of any type) in the sample.

In order to assess the quality of the mixing process, the degree of homogeneity $\mathrm{K}$ of the mixture, according to the following formula must be determined

$$
K=(100-\delta), \%
$$

where $\delta$ - mean square deviation of the calcium carbonate content taken from the sample, compared to the theoretical content. 

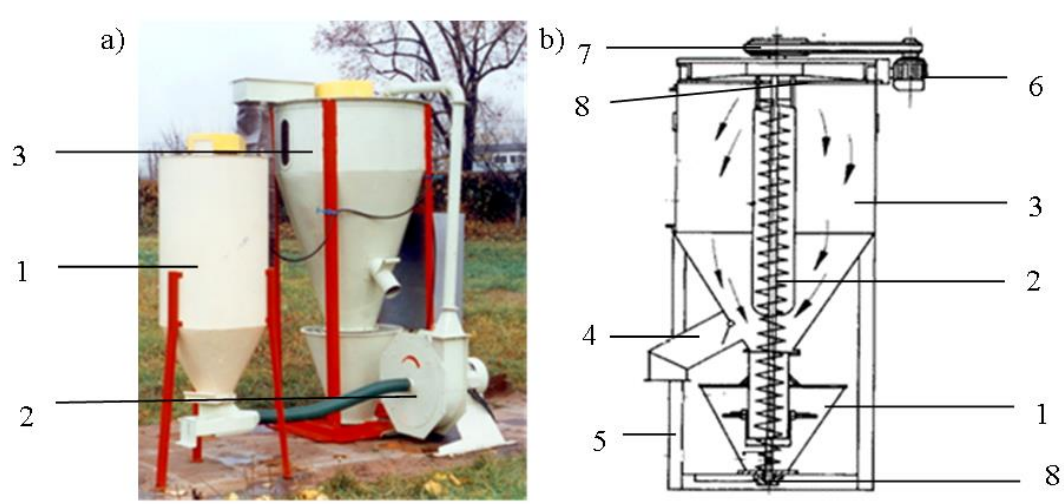

Fig. 2. Fodder flour production installation - IPFF [5]:

$\mathrm{a}$ - installation overview; $\mathrm{b}$ - construction diagram of the installation mixer

According to the error theory, the dispersion of concentrate frequencies around the average values can be characterized by the formula [11]

$$
\delta^{2}=\frac{\sum_{i-1}^{n}\left(X_{i}-\bar{X}\right)^{2}}{n-1},
$$

where the arithmetic mean is given by the relation

$$
\bar{X}=\frac{\sum_{i-1}^{n} X_{i}}{n},
$$

and the sum of the differences between the individual values of the series and the mean is always zero:

$$
\sum_{i-1}^{n}\left(X_{i}-\bar{X}\right)=0 .
$$

When evaluating the measured results, descriptive statistics were applied - the arithmetic mean of the values in the data set, the arithmetic mean being influenced by the extreme values obtained in the experiments. The process of fodder mixing is performed by the action of the mixing auger spiral on the component particles of the mixture, which changes their position, thus obtaining the mixing action. The mixed fodder mixer was tested in the following conditions:

- three speed steps, namely: $n_{1}=200 \mathrm{rpm} ; n_{2}=300 \mathrm{rpm}: n_{3}=400 \mathrm{rpm}$;

- three mixing times, namely: 3, 6 and 15 minutes;

- four mixing ratios, respectively 1:40; $1: 80 ; 1: 120$ and 1: 200.

The mixing ratios were established on the basis of the feed ratios in force according to current norms, considering that the mineral substances, microelements, vitamins and other additives will be mixed beforehand. As an addition, as mentioned before, calcium carbonate has been used, because it is the predominant element that mixes with the basic products.

The experiments were performed with different products depending on the variable mentioned elements, determining the quality of the mixture based on the calcium content. Calcium carbonate was introduced into the mixer at the same time as the base product according to the previously established ratio. After completing the mixing process, the actual calcium carbonate content was determined using an equipment called "calcimeter". The degree of homogeneity $K$ (relation 1 ), $K=100$, represents an ideal mixture, in which the calcium carbonate content added to the base material corresponds to the chosen mixing ratio. For a ratio of $1: 40, K=100$ represents 1 gram of calcium carbonate per 40 grams of base material. According to the literature, the degree of allowed homogenization is between 75 and $100 \%$. During the experiments performed under the conditions mentioned above, the following elements were measured:

- $t_{1}$ - loading time of the material mixer, minutes;

- $t_{2}$ - mixing time, minutes;

- $t_{3}-$ mixer discharge time, minutes; 
- $\quad n$ - mixing screw speed, rpm.

Using the obtained measurements, the following working indices of the mixer subjected to experiments were determined:

- $K$ - degree of homogeneity of the mixture, \%;

- $Q$ - mixing flow rate of the mixer, $\mathrm{kg} \cdot \mathrm{h}^{-1}$;

- $I_{e}-$ economic indices of the mixer.

\section{Results and discussions}

For the experimental phase, the components from Table 1 were used as the raw material. Table 2 in its turn shows the characteristics of the mixing auger.

Characteristics of the raw material used in experiments

Table 1

\begin{tabular}{|c|c|c|c|}
\hline \multirow{2}{*}{ Product } & $\begin{array}{c}\text { Material moisture, } \\
\mathbf{\%}\end{array}$ & $\begin{array}{c}\text { Specific gravity of } \\
\text { the material, } \mathbf{~ k \cdot} \cdot \mathbf{m}^{-\mathbf{3}}\end{array}$ & $\begin{array}{c}\text { Material grinding } \\
\text { granulation, } \mathbf{~ m m}\end{array}$ \\
\hline \multirow{4}{*}{ Corn } & 14.0 & 540 & 1.92 \\
\cline { 2 - 4 } & 18.5 & 518 & 2.08 \\
\cline { 2 - 4 } & 22.0 & 523 & 2.15 \\
\cline { 2 - 4 } & 24.0 & 525 & 2.30 \\
\cline { 2 - 4 } & 26.0 & 535 & 2.60 \\
\hline Green peas & 14.0 & 500 & 1.60 \\
\hline Cereal waste & 14.0 & 354 & 1.60 \\
\hline Bran & 12.4 & 342 & 0.82 \\
\hline Sunflower grist & 12.0 & 465 & 1.81 \\
\hline Mill dust & 12.5 & 244 & 0.96 \\
\hline Calcium carbonate & 2.0 & 940 & 0.50 \\
\hline
\end{tabular}

Table 2

Constructive characteristics of the mixing auger used in experiments

\begin{tabular}{|c|c|c|c|c|}
\hline Characteristic & \multicolumn{4}{|c|}{ Constructive variant } \\
\cline { 2 - 5 } (all measurements in mm) & $\mathbf{1}$ & $\mathbf{2}$ & $\mathbf{3}$ & $\mathbf{4}$ \\
\hline Coil diameter (feeding part) & 220 & 220 & 220 & 220 \\
\hline Coil pitch (feeding part) & 220 & 220 & 110 & 165 \\
\hline Coil diameter (mixing part) & 400 & 300 & 300 & 220 \\
\hline Coil pitch (mixing part) & 300 & 225 & 150 & 165 \\
\hline Length of the coil (feeding part) & 1017 & 937 & 937 & 700 \\
\hline Length of the coil (mixing part) & 735 & 815 & 815 & 1052 \\
\hline
\end{tabular}

In the experiments, corn was used as a basic material. The results obtained for the characteristics of the first mixing auger (variant 1) are presented in Tables 3 and 4 and in Figures 3 and 4.

Results obtained for the base material - corn depending on the speed of the mixing auger

\begin{tabular}{|c|c|c|c|c|c|c|}
\hline \multirow[t]{2}{*}{ Product } & \multirow{2}{*}{$\begin{array}{c}\text { Material } \\
\text { moisture, } \\
\%\end{array}$} & \multirow{2}{*}{$\begin{array}{c}\text { Material grinding } \\
\text { granulation, } \\
\text { mm }\end{array}$} & \multirow{2}{*}{$\begin{array}{c}\text { Mixing } \\
\text { auger speed, } \\
\text { rpm }\end{array}$} & \multicolumn{3}{|c|}{$\begin{array}{l}\text { Degree of homogeneity } K \text { as } \\
\text { a function of } t_{2} \text {, minutes }\end{array}$} \\
\hline & & & & 3' & $6^{\prime}$ & 15 \\
\hline \multirow{3}{*}{ Corn } & \multirow{3}{*}{$22-24$} & \multirow{3}{*}{2.15} & 200 & 74.2 & 91.5 & 95.0 \\
\hline & & & 300 & 69.8 & 85.8 & 92.9 \\
\hline & & & 400 & 63.6 & 83.9 & 90.8 \\
\hline
\end{tabular}

Note: * 9 minutes was not chosen as the mixing time, because from the experiments performed it was found that the values resulting from the experiments differ very little from those with a duration of 6 minutes. 
Results obtained for the base material - corn depending on the mixing ratio

Table 4

\begin{tabular}{|c|c|c|c|c|c|c|}
\hline \multirow{3}{*}{ Product } & \multirow{2}{*}{$\begin{array}{c}\text { Material } \\
\text { moisture, } \\
\text { \% }\end{array}$} & $\begin{array}{c}\text { Material grinding } \\
\text { granulation, } \\
\text { mm }\end{array}$ & \multirow{2}{*}{$\begin{array}{c}\text { Mixing } \\
\text { ratio }\end{array}$} & \multicolumn{3}{|c|}{$\begin{array}{c}\text { Degree of homogeneity } \boldsymbol{K} \text { as } \\
\text { a function of } \boldsymbol{t}_{\mathbf{2}} \text {, minutes }\end{array}$} \\
\cline { 4 - 7 } & \multirow{3}{*}{ Corn } & \multirow{3}{*}{2.15} & $1: 40$ & 69.8 & 94.0 & 96.3 \\
\cline { 4 - 7 } & $22-24$ & & $1: 80$ & 73.4 & 91.2 & 95.9 \\
\cline { 4 - 7 } & & & $1: 120$ & 69.4 & 89.3 & 93.3 \\
\cline { 4 - 7 } & & & $1: 200$ & 69.1 & 79.6 & 91.6 \\
\hline
\end{tabular}

100

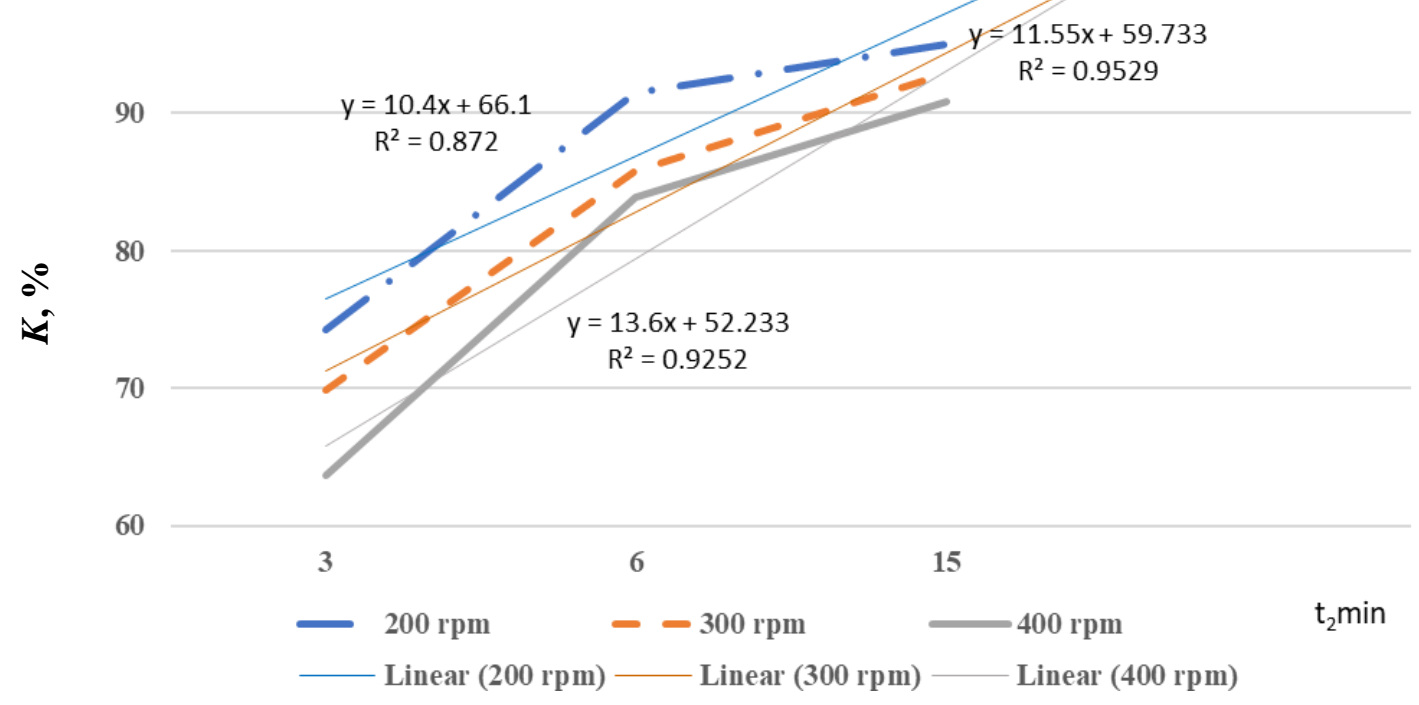

Fig. 3. Variation of the homogeneity degree, depending on auger speed

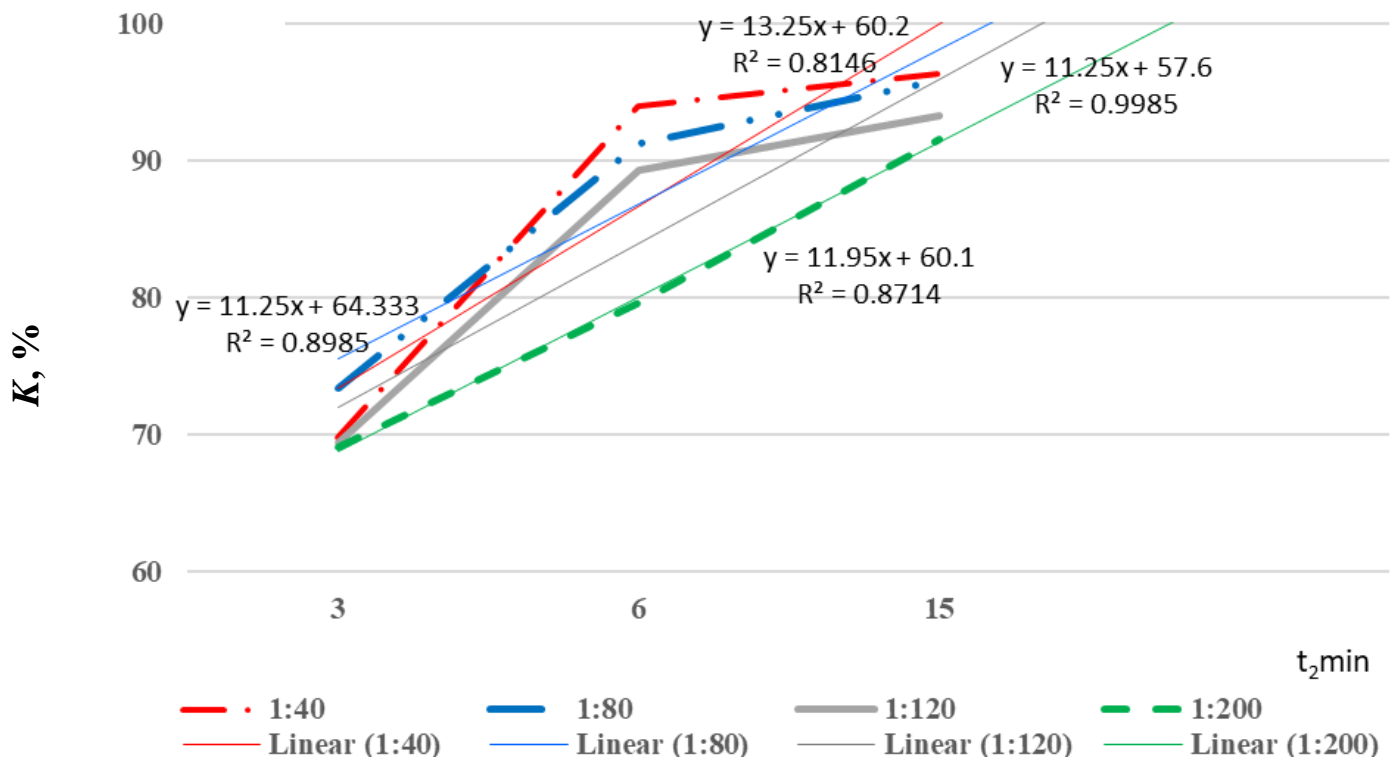

Fig. 4. Variation of the homogeneity degree depending on the mixing ratio

After analyzing the results, using auger variant 1, the following aspects can be deduced according to the figure:

- at the mixing time $t_{2}=3$ minutes, the requirement established for the degree of homogeneity $K$ for any speed is not satisfied;

- for the mixing time of 6 and 15 minutes, for all speeds, the degree of homogeneity $K$ is appropriate and within close values. 
- After analyzing Figure 4, namely the degree of homogeneity $\mathrm{K}$ as a function of mixing ratios, the following aspects can be deduced:

- for the mixing time of 3 minutes, the degree of homogeneity is not satisfied for all the established ratios;

- for the mixing time of 6 and 15 minutes the degree of homogeneity $K$ is satisfied, with the note that for the time of 6 minutes, for the ratio 1: 200 the degree of homogeneity is achieved within the minimum allowed limit.

As mixtures must also be obtained from products with a humidity higher than $18 \%$, experiments were performed with constructive variants 2,3 and 4 , but it was found that they do not satisfy the homogeneity requirement, fodder mixing being unsatisfactory. Experiments with variant 1 for the mixing auger were also performed on the other products from Table 1.

A feed ration consisting of 55\% - corn, $23 \%$ - mill powder, $11 \%$ - bran, $11 \%$ - sunflower meal was made and the variation of the homogeneity degree was analyzed, the results being presented in Figure 5 .

a)



b)

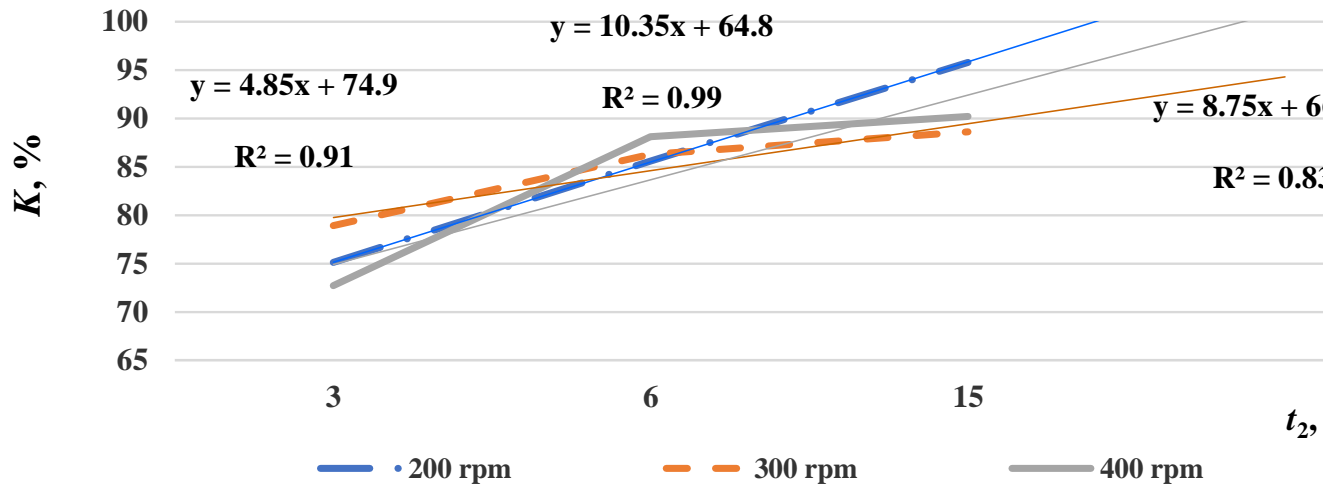

c)



Fig. 5. Variation in the degree of homogeneity depending on the speed of the auger for different products: $\mathrm{a}$ - green peas; $\mathrm{b}$ - cereal waste; $\mathrm{c}$ - feed ration mixture 
For mixing times of 6 and 15 minutes, at all speeds and all products, the degree of homogeneity $K$ has been appropriate.

Because the mixer used in the experiments has two possibilities of loading with material: on the top and the bottom, it must be mentioned that the values presented in this article are specific to the loading on the bottom. However, it was found that if the material is fed on the upper part, the degree of homogeneity it is not significantly affected.

Analyzing Figure 5, it can be seen that the degree of homogeneity is also achieved for the mixing time of 3 minutes. The tests have shown that the power required to mix the products varies between 1 and $3.6 \mathrm{~kW}$.

\section{Conclusions}

Based on the results obtained in the experimental study, the following conclusions can be drawn.

1. The feeding and mixing auger variant 1 with a diameter of $400 \mathrm{~mm}$ and a pitch of $300 \mathrm{~mm}$ is the most suitable for homogeneity requirements, ensuring a satisfactory mixing process for both components with normal humidity (14-18\%) and those with higher humidity (20-25\%).

2. The optimal speed of the auger is $300 \mathrm{rpm}$, because at this speed and the mixing time of 6 and 15 minutes a corresponding degree of homogeneity has been achieved.

3. The best mixing time has been determined to be 6 minutes. The extension of the mixing time from 6 to 15 minutes is not justified neither from the economic point of view, nor from the point of view of the mixture quality.

4. The mixer achieves a degree of homogeneity corresponding to the requirements of all mixing ratios between 1: 400 and 1: 200.

5. The vertical auger mixer performed a mixing process corresponding to the zootechnical requirements for the mixed fodders.

\section{Acknowledgements}

This research work was supported by the grant of the Romanian Research and Innovation Ministry, PN 19100203 contract No. 5N/07.02.2019. Research on intensive fish farming in polyculture system and complex valorization of aquatic bioresources (plants).

\section{References}

[1] Karimirad R., Heshmatollah Kh., Parizadian Kavan B - Effect of different feed physical forms (pellet, crumble, mash) on the performance and liver health in broiler chicken with and without carbon tetrachloride challenge, 1/2020 vol. 29, Lorestan University, Faculty of Agriculture, Department of Animal Sciences, P.B. 465, Khorramabad 68137-17133, Lorestan, Iran.

[2] Cattle, sheep and goats feed, National Institute of Agricultural Research, France, 1994.

[3] Stroescu Ghe., Păun A., Zaica Al, Persu C., Matache A., Zaica A., Bogdanof C-tin., Dumitru I., Yasbeck Khozamy S., Cristea O.D., Cristea L.C., The influence of the mixing process in obtaining concentrated nutrition, Proceedings of International Symposium ISB-INMA TEH' 2020"Agricultural and Mechanical Engineering", Bucharest 29-31 October 2020, Print: ISSN2344-4118, CD-ROM: ISSN2344-4126, ISSN-L 2344-4119, pp. 22-28.

[4] Păun A., Technologies and installations for obtaining concentrated fodder from cereal seeds, Terra Nostra", Iaşi, 2009.

[5] Păun A., Pirna I. Cojocaru I., Optimization of homogenization process inside the installation in order to obtain concentrated fodder IONC, Symposium - INMATEH Agricultural Engineering II, vol.21, ISSN 1583-1019, May 2007, Bucharest, pp. 21-28.

[6] Ben Salem H., Priolo A., Morand-Fehr P., Shrubby vegetation and agro-industrial by-products as alternative feed resources for sheep and goats. Effects on digestion, performance and product quality, Animal Feed Science and Technology, vol. 147, 2008.

[7] Constantin G., Voicu Gh., Stefan E. M., Maican E., Boureci A., Vlăduţ V., Using of logistic function for the analysis of granulometric characteristics of products from the technological flow of a cereal mill, Proceedings of the 42 International Symposium on Agricultural Engineering "Actual Tasks on Agricultural Engineering", 2014, ISSN 1333-2651, Opatija - Croatia, pp. 305314. 
[8] Dumitru O.M., Iorga S., Vlăduţ N.V., Bracacescu C., Food losses in primary cereal production: a review, INMATEH -Agricultural Engineering, vol.63 (3), pp. 133-146, DOI: https://doi.org/10.35633/inmateh-62-14.

[9] Chupshev A., Konovalov V., Fomina M., Optimization in work modeling of a mixer, IOP Conf. Series: Journal of Physics: Conf. Series 1084 (2018) 012010 doi:10.1088/17426596/1084/1/012010.

[10] Fomina M., Konovalov V., Teryushkov V., Chupshev A., The effect of mixing duration and the proportion of smaller component for the performance of the paddle mixer running with extra blades, Journal: Bulletin Samara State Agricultural Academy, Technology, Means of Mechanization and Power Equipment in Agriculture, vol. 2, no. 3, 2017.

[11] Butănescu -Volanin. R. C-tin., Descriptive statistics, version 3, Lucian Blaga University Publishing House, Sibiu, Romania, 2018. 